\title{
An Exploratory Examination of Burnout in NCAA Division II Athletes
}

\author{
Lawrence W. Judge, Robert J. Bell, \\ Rachel Theodore, Laura Simon \\ Ball State University \\ David Bellar \\ University of Louisiana at Lafayette
}

\begin{abstract}
The purpose of this study was to assess the causes of burnout among studentathletes in Division II institutions. The authors distributed the Athlete Burnout Questionnaire (ABQ) to 125 undergraduate student-athletes enrolled at three Division II colleges and universities. The athletes competed in various sports. A 2 (Gender) $\times 2$ (Type of Scholarship) $\times 2$ (School Status) analysis of variance revealed that women and men reported different levels of burnout dependent upon type of scholarship. Men with no scholarship reported the lowest levels of burnout among the three types (None/Academic/Athletic), whereas women with no type of scholarship reported the highest levels of burnout. The authors discuss the results and offer implications, limitations, and future directions.
\end{abstract}

Keywords: burnout, NCAA Division II, collegiate athletes, athlete burnout questionnaire

Participation in collegiate athletics requires an extraordinary amount of energy and dedication. While the intent of college athletics is educational, many coaches are taking a more professionalized approach, even in NCAA Divisions II and III. Student-athletes have to balance class, practice, personal life, and competition on a continuous basis. Juggling a busy athletic season with school can have a huge impact on student-athlete stress levels because, in some cases, the demands and expectations of sport participation can intrude on every other aspect of a studentathlete's life. Research also suggests that athletic participation itself can become an added stressor traditional college students do not experience (Kimball \& Freysinger, 2003; Papanikolaou, Nikolaidis, Patsiaouras, \& Alexopoulos, 2003). Persistent levels of personal stress can lead to athletic burnout.

Judge, Bell, Theodore, and Simon are with the Department of Physical Education, Sport, and Exercise Science, Ball State University, Muncie, IN. Bellar is with the Kinesiology Dept., University of Louisiana at Lafayette, Lafayette, LA. 


\section{Burnout}

Whereas a variety of definitions for burnout exist, Raedeke's (1997) definition encompasses burnout as a syndrome of three different elements: physical or emotional exhaustion, sport devaluation, and reduced athletic accomplishment. Emotional and physical exhaustion can be characterized by feelings of fatigue related to sport performance, training, and competition. Sport devaluation occurs when an athlete no longer views the sport context as worth the current level of personal investment (Raedeke, 1997). The impact of these two factors can lead to reduced athletic accomplishment because of the impact on personal motivation and morale. Signs and symptoms of burnout can be psychological, behavioral, or physical (Raedeke, Lunney, \& Venables, 2002), with the most common themes reported as decreased performance, psychological distress, feelings of helplessness or entrapment, and lack of enjoyment (Lemyre, Treasure, \& Roberts, 2006; Struhar, 2003).

\section{Causes of Burnout}

The prevalence of burnout among athletes remains speculative. Some researchers show that burnout was experienced by as much as 6-11\% of athletes (Cresswell \& Eklund, 2007). In contrast, Gustafsson, Kentta, Hassmen, and Lundqvist (2007) examined the prevalence of burnout in 980 Swedish adolescent athletes ranging in ages 16-21 years old and found that between only $2 \%$ and $6 \%$ of men and $1-9 \%$ of women experienced high levels of burnout. The overall percentage of athletes experiencing burnout appears relatively small because a classification of burnout required a high score on all three elements of the standard test (i.e., emotional exhaustion, sport devaluation, and reduced athletic accomplishment). Thus, individuals may not be identified as being "burned out" if they score high on only one component. Nonetheless, this should not minimize the severity of the issue, when, in fact, the extent of this problem has yet to be determined (Cresswell \& Eklund, 2007).

Numerous scholars have examined the causes of burnout among athletes including but not limited to: increased stress (Lai \& Wiggins, 2003), physical and emotional exhaustion (Lemyre et al., 2006), intense workload, injury (Cresswell $\&$ Eklund, 2006a), pressure from coaches (Price \& Weiss, 2000), performance and parental pressure (Coakley, 1992; Gould, Tuffey, Udry, \& Loehr, 1997; Raedeke et al., 2002), and feelings of entrapment (Raedeke, 1997). These causes of burnout appear to be multifaceted (Coakley, 2009) and several models and theories of burnout exist (for a complete review see Gould \& Whitley, 2009). However, most burnout research has neglected situational and demographic circumstances of burnout (Goodger, Gorely, Lavallee, \& Harwood, 2007).

Although burnout research has examined younger athletes (see Price \& Weiss, 2000), most research has focused on NCAA Division I student-athletes and/or professionals (Gould \& Whitley, 2009; Lai \& Wiggins, 2003). Unlike NCAA Division I sports, where student-athletes are recruited and there is often a substantial amount of scholarship money available, Division II student-athletes have more limited scholarship funding and, because of this, may not experience the same types of stress (Miller \& Kerr, 2002). To elaborate, there are 331 NCAA Division I athletic programs with the median operating expenses at $\$ 15.1$ million per institution. Schools with no football (no FB) operate at approximately $\$ 10.3$ 
million compared with schools in the FBS (football bowl subdivision) with $\$ 41.3$ million in expenses (Fulks, 2010).

By way of comparison, Division II institutions' median athletic expenses are $\$ 3.8$ million (Fulks, 2010). However, the NCAA also stresses balance of the studentathlete experience at the Division II level, emphasizing both highly competitive athletics along with the institutional academic mission (Fulks, 2010). In addition, whereas few of the student-athletes at the Division II level receive full financial scholarships, many Division II institutions operate on the partial-scholarship model in which student-athletes pay for school through academic aid, loans, grants, and employment earnings (see Fulks, 2010).

In a recent review of literature, Gould and Whitley (2009) called for the continued study of burnout within collegiate athletes, to explore the development of burnout over time. It is possible that the causes of burnout among Division I and II student-athletes vary due to the ideological differences between divisions.

Because athletes may also be on academic scholarships and have a job, burnout on the Division II level may be associated more with time management and maintaining adequate grade point averages. This problem of balancing academics and athletics has also been previously found within Australian football (Noblet \& Gifford, 2002). In fact, academic stressors experienced by university athletes have been identified as a cause of burnout (Heller, Bloom, Neil, \& Salmela, 2005; Miller $\&$ Kerr, 2002; Settles, Sellers, \& Damas, 2002). Heller et al. (2005), in a qualitative study with Division I female hockey players, revealed that a major source of stress was educational demands. This stress resulted from concerns governing completing and making up schoolwork, maintaining good grades, and managing one's time. With this type of emphasis placed on a busy sports schedule, it is not unusual that burnout has become almost synonymous with sports across collegiate campuses.

\section{Gender Differences}

In addition, differences in female and male athlete burnout have only been studied at the Division I and high school levels. Research findings have varied from no significant differences between women and men (Lai \& Wiggins, 2003) to significant differences in gender depending on the context of team or individual sports (Gustafsson et al., 2007). In a study of burnout with collegiate males and females, Weckwerth and Flynn (2006) found that women experienced higher levels of burnout because they were not receiving social support congruent with their needs. Similarly, Kelley (1994) suggested that women had higher levels of burnout due to perceived stress and emotional exhaustion. Women were expected to not only be successful at their sport, but also be nurturing, supportive members of their team, something men did not report as a pressure. Research has also shown that women are more likely to use social support in times of need more so than do men (Ptacek, Smith, \& Zanas, 1992).

Given that women's sport participation in American colleges and universities has increased dramatically since the passage of Title IX, it is surprising that research in such areas remains underdeveloped. Because of the different experiences of Division II student-athletes noted by the NCAA and the lack of research on gender differences, it is imperative to explore not just Division II athlete burnout, but also gender variations in burnout at all levels. Riddell and Tett (2010), investigating gender differences in teachers, concluded that the nature of the performance is 
constrained by a range of social pressures and forces which shape the conditions in which women and men make choices about their lives. Women and men potentially vary in how they make choices, differences that might carry over to burnout, too.

\section{Current Study}

Understanding the causes of burnout among specific athletic populations may provide further insight into potential social-cultural differences and possible intervention modalities. Burnout is a concern for the social welfare of the studentathletes and should be an issue that merits further study by the NCAA. Therefore, the purpose of the current study was to examine the causes of burnout in NCAA Division II student athletes and identify any possible differences in burnout between women and men NCAA Division II student-athletes.

Two research questions guided this exploratory study:

Research Question 1: What were the causes of burnout among Division II student-athletes?

Research Question 2: What were the differences in burnout between male and female Division II student-athletes?

\section{Method}

\section{Participants}

Participants for this study consisted of 125 undergraduate student-athletes across three different Division II colleges and universities located in the Midwest and East Coast regions. To obtain a representative sample of Division II institutions, participants were recruited from schools that sponsored basketball, football, and track and field programs. Of the 125 completed questionnaires, 59.2\% were women $(n=74)$ and $40.8 \%$ were men $(n=51)$. The participants ranged in age from 18 to 24 years old $(M=19.90, S D=1.8)$. The majority of the participants were White $(n=116)$, while the other participant races were as follows: African American $(n$ $=5)$, Hispanic American $(n=2)$, and other $(n=3)$. Sixty percent of the participants were sophomores and first year student, juniors made up $19.2 \%$ percent of the participants, $13.6 \%$ were seniors, and $7.2 \%$ were of another academic grade (possibly a 5th year student or a graduate student).

Track and field/cross country athletes $(n=97)$ comprised the majority of participants, followed by basketball $(n=28)$ (see Table 1$)$. The majority of participants $(n$ =67) received partial scholarships, with an equal number of participants receiving full scholarships $(n=29)$ and/or no scholarship $(n=29)$ (see Table 2). Academic $(n=51)$ and Athletic $(n=47)$ were the most often reported types of scholarship, while 27 participants reported they did not receive any scholarship).

\section{Measures}

A demographic questionnaire and the Athlete Burnout Questionnaire (Raedeke \& Smith, 2001) were used in this study. The demographic questionnaire consisted of seven items and collected information regarding age, gender, ethnicity, school status (i.e., academic/athletic grade), scholarship amount and type, and current 
Table 1 Frequencies and Percentages by Sport(s) Played

\begin{tabular}{lll}
\hline Sport & Frequency (N) & Percentage (\%) \\
\hline Basketball & 28 & 22.4 \\
Track and Field/Cross Country & 97 & 77.6 \\
\hline
\end{tabular}

Note. "N" = Total Sample of Student-Athletes

Table 2 Frequencies and Percentages by Amount of Scholarship (i.e. None, Partial, or Full)

\begin{tabular}{lll}
\hline Amount of Scholarship & Frequency (N) & Percentage (\%) \\
\hline None & 29 & 23.2 \\
Partial & 67 & 53.6 \\
Full & 29 & 23.2 \\
\hline
\end{tabular}

Note. "N" = Total Sample of Student-Athletes

level of participation in intercollegiate athletics (i.e., sport played). The Athlete Burnout Questionnaire (ABQ) was developed to assess athlete burnout. The ABQ is composed of three five-item subscales designed to measure: (a) reduced sense of accomplishment (e.g., "It seems that no matter what I do, I don't perform as well as I should"), (b) devaluation (e.g., "I have negative feelings toward sport"), and (c) emotional/physical exhaustion (e.g., "I am exhausted by the mental and physical demands of my sport"). Participants responded to items on a five-point Likert-type scale anchored by descriptors of "almost never" (1), "rarely" (2), "sometimes" (3), "frequently" (4), and "most of the time" (5). Internal consistency has been reported previously by the ABQ authors as $>.70$ for the subscales, with test-retest reliability ranging from .86 to .92 on the three scales and acceptable construct validity (Raedeke \& Smith, 2001).

\section{Procedures}

Before data collection, the researchers' University Institutional Review Boards approved all of the procedures. We randomly selected head coaches at NCAA Division II programs, contacted via e-mail, and sent a link to the online questionnaire. Participants then completed the online informed consent, demographic survey, and Athlete Burnout Questionnaire by clicking on the answers that most closely applied to them.

\section{Results}

Some statistical procedures (analysis of variance and $t$ test) assume that variances are equal across each group of the independent variables (Coladarci, Cobb, Minium, \& Clarke, 2003). Levene's Test of Equality of Error Variance was a method used to test this assumption. For the current study of 125 participants, Levene's Test of 
Equality of Variances revealed that equal variances existed across groups, $F$ (46, $77)=.393, p<.05$.

To explore significant differences in causes of burnout, we computed a 2 $($ Gender $) \times 2$ (Year) $\times 2$ (Type of Scholarship) analysis of variance (ANOVA). The subscales of Emotional/Physical Exhaustion, Reduced Athletic Accomplishment, and Sport Devaluation were examined using two separate ANOVAs. We computed two analyses, a 2 (Gender) $\times 2$ (Year) $\times 2$ (Scholarship) ANOVA and 2 (Gender) $\times 2$ (Scholarship Amount) $\times 2$ (Sport Played) ANOVA, using each subscale as the dependent variable. The lack of diversity and the small sample size of the subject population in the current study did not allow for findings based on race.

\section{Significant Causes of Burnout and Male/Female Differences}

Regarding the significant causes of burnout, results revealed a significant Gender $\times$ Type of Scholarship interaction, $F(2,96)=3.84, p<.05$. Women and men reported different levels of burnout dependent upon the type of scholarship they possessed. Specifically, men $(M=29.14, S D=2.75)$ with no scholarship reported the lowest levels of burnout among the three types (None/Academic/Athletic), whereas women $(M=43.32, S D=3.81)$ with no scholarship reported the highest levels of burnout. No significant results were found for year in school, $F(4,112)=1.413, p>.05$, or scholarship amount, $F(2,112)=.135, p>.05$.

\section{Student-Athlete Sport Participation}

No significant results were found for the main effect sport played, $F(1,121)=.649$, $p>.05$, or the interaction effect of Sport Played $\times$ Gender, $F(1,121)=.493, p>.05$.

\section{Emotional/Physical Exhaustion}

Regarding potential differences between the Athlete Burnout Questionnaire subscales, we found two significant effects, the first of which was a significant Gender $\times$ Year interaction, $F(4,97)=2.932, p<.05$. Junior men and women reported significant differences of emotional and physical exhaustion. Specifically, junior men had the highest levels of emotional and physical exhaustion $(M=16.08, S D=$ 3.69), while junior women had significantly lower levels of emotional and physical exhaustion $(M=11.42, S D=3.09)$.

In addition, we observed a Gender $\times$ Type of Scholarship interaction for Emotional/Physical Exhaustion, $F(2,97)=4.17, p<.05$. Men with no type of scholarship reported the lowest levels of emotional and physical exhaustion $(M$ $=9.73, S D=2.95)$, while women with no scholarship reported the highest levels of physical and emotional exhaustion $(M=14.85, S D=3.72)$. We observed no significant differences for Gender $\times$ Sport Played, $F(1,115)=2.40, p>.05$, or Gender $\times$ Scholarship Amount, $F(2,115)=1.79, p>.05$.

\section{Reduced Athletic Accomplishment}

We observed a significant scholarship main effect for the Reduced Athletic Accomplishment subscale, $F(2,115)=3.12, p<.05$. Amount of scholarship (none, partial, or full) had an effect on the student-athlete's lack of athletic accomplishment. 
Specifically, student-athletes with no scholarship $(M=13.33, S D=3.76)$ reported higher levels of reduced athletic accomplishment than student-athletes with full scholarships $(M=10.08, S D=3.59)$. We did not observe a significant Scholarship Amount $\times$ Gender, $F(2,115)=2.17, p>.05$, or Scholarship Amount $\times$ Sport, $F$ $(2,115)=.912, p>.05$, interaction.

Another significant main effect was revealed on the subscale of Reduced Athletic Accomplishment in scholarship type, $F(2,97)=3.93, p<.05$. Type of scholarship (none, academic, or athletic) had an impact on burnout levels in all the participants on the subscale of Reduced Athletic Accomplishment. Specifically, athletes with no scholarships $(M=12.52, S D=3.56)$ had higher levels of reduced athletic accomplishment than athletes on athletic scholarships $(M=10.18, S D=$ 3.50). Although we observed a significant Scholarship Type main effect was found, we did not find significant Scholarship Type $\times$ Gender, $F(2,97)=2.54, p>.05$, or Scholarship Type $\times$ Year, $F(8,97)=.89, p>.05$, interaction.

\section{Sport Devaluation}

We did not find any significant main effects of gender, $F(1,115)=.09, p>.05$, scholarship amount, $F(2,115)=1.635, p>.05$, sport, $F(1,115)=.13, p>.05$, scholarship type, $F(2,97)=.86, p>.05$, or academic year, $F(4,97)=1.89, p>$ .05 , nor did we find significant interaction terms for sport devaluation.

\section{Discussion}

To date, burnout research has focused on selected demographics including professional, Division I, and youth athletics. In this exploratory study, we extended this literature by examining burnout among women and men competing in Division II athletics. We examine the primary findings in the following space.

First, burnout research has been hampered by a lack of a theoretically based and empirically sound measurement tool (Gould \& Whitley, 2009). Past research has shown that self-reported questionnaires and limited comparable data can create difficulties in assessing result reliability (Alaranta et al., 2006). The utilization of the athlete burnout questionnaire (ABQ) in the current study clarifies the need for the development of a more suitable instrument for measuring burnout in a standardized and consistent manner (Cresswell \& Eklund, 2006b).

Second, results of the current study revealed significant findings regarding scholarship status. Data analysis revealed that women and men displayed significantly different levels of burnout based on type of scholarship. Specifically, men with no scholarship reported the lowest levels of burnout, whereas women with no scholarship reported the highest levels of burnout. Recall that previous research suggests women report higher levels of burnout than do men (Kelley, 1994; Lai \& Wiggins, 2003). However, our findings suggest a more nuanced approach is warranted, as gender differences were moderated by scholarship status; thus, women expressed more burnout than did men in some situations, but not others.

Third, some researchers have suggested that recipients of athletic scholarships at the Division II level contribute to the academic profile, gender balance, and cultural diversity of the institution as well as increasing net-revenue (HardwickDay, 2008). However, institutional academic profiles and the credentials of those 
holding athletic scholarships reveal gender differences between recipients. Athletic scholarship holders who are women were found to be in the top tier academically. Women with higher academic achievement may have more intrinsic motivation to study and work harder which results in higher grades. Comparatively, men who received athletic scholarships were less likely to possess high level academic profiles (Hardwick-Day, 2008). This may be an important distinction for future research due to the possible confounding effect of academic ability or academic aspiration on burnout levels in the current study.

Raedeke (1997) proposed the entrapment model of burnout, in that, athletes felt that they "had to" participate, which caused burnout susceptibility. However, the "entrapped" athlete feels she or he cannot discontinue because of the repercussions and that too much time and effort have been devoted toward their sport. Results from the current study may suggest that men with no scholarship felt the least amount of stress to maintain academic standards and experienced lowered feelings of entrapment. On the other hand, women with no scholarship, even though generally in the top tier academically (Hardwick-Day, 2008), may have experienced burnout due to a difference in athletic climate. Research has reported that a source of stress, in particular for women competing at the DI level, has been upholding the public image of being a student-athlete and maintaining the status as a role model within the community (Heller et al., 2005; Miller \& Kerr, 2002). Higher burnout rates among women without scholarships may be a result of them experiencing less satisfaction from their participation than their peers with scholarship aid. This may occur since the nonscholarship athletes may feel less relatedness, competence and autonomy (Cresswell \& Eklund, 2005, 2006a) as they often exert the same amount of effort but do not receive any of the monetary benefits that their scholarship peers receive.

It is also possible that the motivational climate contributed to the differences in burnout scores between women and men. Raedeke (1997) suggested that a common theme among athletes experiencing burnout appears to be motivation. Simply put, athletes with high levels of intrinsic motivation, perceive themselves as competent and autonomous, and have lower negative associations with burnout (Cresswell \& Eklund, 2005). In addition, Amorose and Horn (2000) found that athletes with scholarships reported higher levels of intrinsic motivation than nonscholarship athletes.

It is important to analyze the various elements that contribute to burnout in the current study. Price and Weiss (2000) found that coaches had an influence on their athletes' burnout levels at the professional level, so it is plausible that coaches within the current study also affected motivation and burnout levels. In addition, Udry, Gould, Bridges, and Tuffey (1997) found that positive influence from coaches (support, empathy, belief in athletes, instruction) was related to lower burnout scores whereas negative coaching influence (pressure, unrealistic expectations, conflicting ideas, lack of confidence in athlete) was related to higher levels of burnout in athletes.

One missing element that may also impact burnout levels is the gender of the coach. Gender specific coaching styles vary and as do the coaching preferences of the different genders. These differences could possibly have an impact on burnout. Student-athletes should be provided with appropriate opportunities for social support from the coaching gender they prefer. But this is often a challenge as the majority of NCAA collegiate coaches are males. After the passage of Title IX, the number of women in athletic leadership positions actually decreased (Bradford 
$\&$ Keshock, 2009) on the collegiate level. The percentage of women coaching female athletes has decreased by $48 \%$ from 1972 to 2008 and is steadily decreasing (Acosta \& Carpenter, 2008; National Collegiate Athletic Association [NCAA], 2009). Similarly, the number of women coaching female sports has decreased and the number of women coaching male sports has historically been consistently rare. Since gender was found to be an important variable predicting burnout the influence of the gender of the coach could be an additional variable for future investigation. This topic was beyond the scope of the current study.

\section{Limitations and Future Directions}

Though the study makes several contributions, there are limitations. Primarily, a limitation of the current research design was that only three Division II schools participated with 125 total participants, most of whom were White. Thus, the study has limited generalization to other contexts. Nonetheless, the current results may serve as a bridge for further development of burnout research.

The current study potentially provides a rationale for future research to properly assess burnout among male/female groups with no scholarships. Along with additional suggestions by Gould and Whitley (2009), future burnout research should continue to assess motivational factors such as scholarship status of all athletes. One avenue may be incorporating a qualitative methodology for participants either within intervention or longitudinal designs. Since a number of potential correlations (e.g., stress, pressure, entrapment) have been identified as causes of burnout, utilizing different methodologies is logical. Thus, repeated measures of the ABQ along with a triangulation of qualitative data across the season are warranted. Future research may also be best served exploring specific teams, coaches, win/loss records, and commitment levels to better understand the extent of motivation and burnout.

\section{Conclusion}

In the current study, access to or receipt of college scholarships may have an influence on burnout levels in student-athletes. Significant differences were found for burnout scores between women and men with no scholarship and groups with scholarship at the Division II level. Combined, these results support previous research suggesting the importance of scholarship in influencing motivation (Amorose \& Horn, 2000). These differences in gender and scholarship could be due to a number of motivational factors, but social support and coaching behavior may have also been moderating variables within this study. Additional studies are needed to analyze the reasons for the disparate differences in gender experience related to scholarship level. Despite the inconclusive impact of gender differences on burnout, the influence of scholarship is apparent on Division II student-athletes.

\section{References}

Acosta, R. V., \& Carpenter, L. J. (2008). Women in intercollegiate sport: A longitudinal, national study thirty one year update: 1977-2008. Retrieved from Women's Sport Foundation website: http://www.womenssportsfoundation.org/Content/Articles/Issues/ 
Participation/W/Womn-in-Intercollegiate-Sport-A-Longitudinal-National-StudyThirty-One-Year-Update-19772008.aspx

Alaranta, A., Alaranta, H., Holmila, J., Palmu, P., Pietilä, K., \& Helenius, I. (2006). Self-reported attitudes of elite athletes towards doping: Differences between type of sport. International Journal of Sports Medicine, 27(10), 842-846. PubMed doi:10.1055/s-2005-872969

Amorose, A., \& Horn, T. (2000). Intrinsic motivation: Relationships with collegiate athletes' gender, scholarship status, and perceptions of their coaches' behavior. Journal of Sport \& Exercise Psychology, 22, 63-84.

Bradford, S. H., \& Keshock, C. M. (2009). Female coached and job stress: A review of the literature. College Student Journal, 43(1), 196-200.

Coakley, J. (2009). Burnout as an organizational issue. Journal of Intercollegiate Sports., 2, 35-41.

Coakley, J. (1992). Burnout among adolescent athletes: A personal failure or social problem? Sociology of Sport Journal, 9, 271-285.

Coladarci, T., Cobb, C.D., Minium, E.W., \& Clarke, R.C. (2003). Fundamentals of statistical reasoning in education. Hoboken, NJ: John Wiley \& Sons, Inc.

Cresswell, S., \& Eklund, R. (2005). Changes in athlete burnout and motivation over a 12-week league tournament. Medicine and Science in Sports and Exercise, 37, 1957-1966. PubMed doi:10.1249/01.mss.0000176304.14675.32

Cresswell, S., \& Eklund, R. (2006a). The nature of player burnout in rugby: Key characteristics and attributions. Journal of Applied Sport Psychology, 18, 219-240. doi:10.1080/10413200600830299

Cresswell, S., \& Eklund, R. (2006b). The convergent and discriminant validity of burnout measures in sport: A multi-trait/multi-method analysis. Journal of Sports Sciences, 24, 209-220. PubMed doi:10.1080/02640410500131431

Cresswell, S., \& Eklund, R. (2007). Athlete burnout: A longitudinal qualitative investigation. The Sport Psychologist, 21, 1-20.

Fulks, D.L. (2010). NCAA Division II intercollegiate athletics programs report. Retrieved from www.ncaapublications.com/productdownloads/2008DIIRevExp.pdf

Goodger, K., Gorely, T., Lavallee, D., \& Harwood, C. (2007). Burnout in sport: A systematic review. The Sport Psychologist, 21, 125-149.

Gould, D., \& Whitley, M.A. (2009). Sources and consequences of athletic burnout among college athletes. Journal of Intercollegiate Sport, 2, 16-30.

Gould, D., Tuffey, S., Udry, E., \& Loehr, J. (1997). Burnout in competitive junior tennis players: III. Individual differences in the burnout experience. The Sport Psychologist, 11, 257-276.

Gustafsson, H., Kentta, G., Hassmen, P., \& Lundqvist, C. (2007). Prevalence of Burnout in Competitive Adolescent Athletes. The Sport Psychologist, 21, 21-37.

Heller, T.L., Bloom, G.A., Neil, G.I., \& Salmela, J.H. (2005). Sources of stress in NCAA Division 1 women ice hockey players. Athletic Insight: The Online. Journal of Sport Psychology, 7.

Kelley, B. (1994). A model of stress and burnout in collegiate coaches: Effects of gender and time of season. Research Quarterly for Exercise and Sport, 65, 48-58. PubMed

Kimball, A., \& Freysinger, V.J. (2003). Leisure, stress, and coping: The sport participation of collegiate student-athletes. Leisure Sciences, 25, 115-141. doi:10.1080/01490400306569

Lai, C., \& Wiggins, M. (2003). Burnout perceptions over time in NCAA division I soccer players. International Sports Journal, 7, 120-128.

Lemyre, P., Treasure, D., \& Roberts, G. (2006). Influence of variability in motivation and affect on elite athlete burnout susceptibility. Journal of Sport \& Exercise Psychology, $28,32-49$.

Miller, P.S., \& Kerr, G. (2002). The athletic, academic and social experiences of intercollegiate student-athletes. Journal of Sport Behavior, 25, 346-367. 
National Collegiate Athletic Association [NCAA]. (2009). Gender equity in college coaching and administration: Perceived barriers report. Retrieved from NCAA Publications website: http://www.ncaapublications.com/c-58-academic.aspx ?pagenum $=5 \&$ view $=0$

Noblet, A.J., \& Gifford, S.M. (2002). The sources of stress experienced by professional Australian footballers. Journal of Applied Sport Psychology, 14, 1-13. doi:10.1080/10413200209339007

Papanikolaou, Z., Nikolaidis, D., Patsiaouras, A., \& Alexopoulos, P. (2003). The freshman experience: High stress-low grades. Athletic Insight: The On-line. Journal of Sport Psychology, 5.

Ptacek, J., Smith, R., \& Zanas, J. (1992). Gender, appraisal, and coping: Longitudinal analysis. Journal of Personality, 60, 747-770. doi:10.1111/j.1467-6494.1992.tb00272.x

Price, M., \& Weiss, M. (2000). Relationships among coach burnout, coach behaviors, and athletes' psychological responses. The Sport Psychologist, 14, 391-409.

Raedeke, T. (1997). Is athlete burnout more than just stress? A sport commitment perspective. Journal of Sport \& Exercise Psychology, 19, 396-417.

Raedeke, T., \& Smith, A. (2001). Development and preliminary validation of an athlete burnout measure. Journal of Sport \& Exercise Psychology, 23, 281-306.

Raedeke, T., Lunney, K., \& Venables, K. (2002). Understanding athlete burnout: Coach perspectives. Journal of Sport Behavior, 25, 181-207.

Riddell, S., \& Tett, L. (2010). Gender balance in teaching debate: tensions between gender theory and equality policy. International Journal of Inclusive Education, 14(5), 463-477. doi:10.1080/13603110802522541

Settles, I.H., Sellers, R.M., \& Damas, A., Jr. (2002). One role or two? The function of psychological separation in role conflict. The Journal of Applied Psychology, 87, 574-582. PubMed doi:10.1037/0021-9010.87.3.574

Struhar, C. (2003). Ten tell-tale signs of burnout. Coach \& Athletic Director, 73, 38-40.

Udry, E., Gould, D., Bridges, D., \& Tuffey, S. (1997). People helping people? Examining the social ties of athletes coping with burnout and injury stress. Journal of Sport \& Exercise Psychology, 19, 368-396.

Weckwerth, A., \& Flynn, D.M. (2006). Effect of sex on perceived support and burnout in university students. College Student Journal, 40, 237-249. 